\section{La educación artística como elemento clave en el proceso de aprendizaje en la escuela}

Art Education as a Key Element during the Learning Process in Elementary School
¿Es la educación artística clave en el proceso de aprendizaje? Ante esta pregunta es probable que una mayoría responda negativamente, pese a su innegable papel tanto en la expresión y canalización de emociones, como en el desarrollo cultural de los estudiantes a través de actividades como jugar, crear o compartir.

¿Podemos considerar el tándem educación/arte como una vía importante de motivación y aprendizaje activo durante la etapa preescolar?

Este articulo pretende defender la educación artística como reEste articulo pretende defender la educacion artistica como recurso esencial en la educación infantil, ayudándose de análisis y comparativas entre las estrategias utilizadas habitualmente en aulas españolas. Además de otros modelos y propuestas de destacados profesores $\mathrm{y}$ artistas.

Is art education key during the learning process? When this quiestionis being asked, a majority would have negative response, even though is undeniable role in expresion and canalisation of even though is undent a mation of emotions, as well as in the cultural development of the students through different activities such as playing, creating and sharing Is it possible to consider the eduation/art tandem as an important source of motivation and active learning during preschool? This article pretends to support art education as an essential resource in preschool education, relying on analyses and comparisons between several strategies used in Spanish art schools. As well as several methods used by remarkable artists and lecturers.

¿Es clave la educación artística en el proceso de aprendizaje? Ante esta pregunta es probable que una mayoría responda negativamente, alegando que la educación pedagógica es la clave del aprendizaje. La RAE define la educación como "la acción y efecto de educar" 1 , mientras que el arte es la "manifestación de la actividad humana mediante la cual se expresa una visión personal y desinteresada que interpreta lo real o imaginado con recursos plásticos, lingüístico o sonoros" ${ }^{2}$. Parece innegable que la educación artística ayuda al sujeto a canalizar sus emociones a través de la expresión artística, contribuyendo por tanto al desarrollo cultural de los seres humanos.

El arte siempre ha sido una acción activa, con un rol potencialmente imprescindible en la educación de nuestros infantes. El dibujo, la pintura o las piezas de construcción constituyen un desarrollo complejo en el que el niño agrupa variedad de componentes de su experiencia para formar un todo con un nuevo significado. En el proceso de seleccionar interpretar y reformar esos componentes, el niño nos da algo más que un dibujo o una escultura, nos aporta una parte de sí mismo en ese instante: cómo piensa, cómo siente y cómo ve.

La educación formal tiene un papel extraordinario, fundamentalmente cuando analizamos el hecho de que el período de escolarización -desde los seis hasta los dieciséis, ya que en el caso de los preescolares (5años) no es obligatorio dentro del ámbito español- se les exige, por razones legales, a permanecer diez años dentro de las instituciones académicas. El cumplimiento de este derecho posibilita al joven establecer su lugar en la sociedad como miembro e individuo útil y bien adaptado. Desde determinados puntos de vista, la educación cumple con este cometido. Podemos observar claramente hoy, en la actualidad, muchos progresos materiales. No obstante, se abren ciertas cuestiones sobre nuestra capacidad de educar más allá de la producción y consumo de objetos. ¿Nuestros sistemas de educación han tenido realmente en cuenta los valores humanos?, o ¿nos hemos centrado únicamente en el beneficio material, dejando de lado los valores de la sociedad moderna, residentes en su bien más preciado, el grupo?

Hoy en día nuestro sistema de educación da mucha importancia al adecuado aprendizaje de información referida a hechos. En gran medida, el aprobado y no aprobado de un examen o pasar un curso, para el próximo, o incluso permanecer en la escuela, dependen del dominio o de la memorización de ciertos fragmentos de información que ya conoce el maestro. De este modo, la función de la enseñanza parecería reducirse a formar gente capaz de coleccionar partes de información y repetirla a una señal dada. Una vez que el estudiante ha conseguido cierta competencia para proporcionar los fragmentos de información adecuados en las circunstancias oportunas, se le considera como aprobado para graduarse en esa escuela. Lo más fastidioso de esta situación es que esa capacidad para repetir información puede tener muy poca relación

1 Diccionario de la Real Academia Española, RAE. Fuente: http://www rae.es ICons 2 Ibidem con aquel concepto de miembro útil y bien adaptado que suponíamos estar formando. 
No intentamos dar la impresión de que por el sencillo hecho de desarrollar un buen programa de creación artística en la escuela se salve a la humanidad; no obstante los valores que son significativos en un programa de educación artística son los mismos que pueden ser elementales en el desarrollo de una nueva imagen, una nueva filosofía y también de una organización totalmente nueva de nuestro sistema educacional. Montessori reconoce que "la aptitud para aprender, implica no solamente capacidad intelectual, sino también factores sociales, emocionales, perceptivos, físicos y psicológicos" 3 . Asimismo, el aprendizaje es un desarrollo o evolución muy complejo; por lo que probablemente no

exista una única forma de enseñanza. Nuestra preferencia a desarrollar la capacidad de repetir trozos de información puede estar acentuando indebidamente un factor del desarrollo humano, aquel que actualmente se evalúa por medio de los test de inteligencia. La inteligencia, ta como ahora medimos, no engloba todo el amplio rango de aptitudes intelectuales que son imprescindibles, mejor dicho necesarias, para la supervivencia de la humanidad. La capacidad de cuestionar, de hallar respuestas, de descubrir orden y formas, de volver a pensar, reestructurar y buscar nuevas relaciones, son cualidades que frecuentemente no se enseñan en la actualidad.

En resumen, el arte establece una forma o medio por el que todas las personas en el mundo puedan expresarse sana y libremente. Tiene mucho valor ya que sin él, la vida y lo que la constituye no serían lo mismo. La percepción en la que un niño aprecia el vuelo de las mariposas, es arte. Para los más pequeños, el arte es de vital importancia, es un medio de expresión del pensamiento. Cada niño ve el mundo de forma distinta y, a medida que se va desarrollando como persona, su forma de expresión se va transformando. "Se ha demostrado científicamente que el estudio de las bellas artes, desde edad temprana, cultiva en el ser humano una sensibilidad que lo lleva a desarrollar una ética muy sólida en su vida adulta"4.

Ningún argumento más poderoso y convincente que ver el torrente de actividad creativa que los niños despliegan cuando les ofrecemos un espacio en el que puedan desarrollarse artísticamente. Todas las artes (las que nombramos anteriormente, como el dibujo, la literatura, la música, etc.) pertenecen a cada uno de los individuos que permiten crear libremente un mundo a partir de su propia interpretación. Los niños comprenden y expresan el mundo de otro modo. Todos los grandes pedagogos del siglo pasado como Dewey, Claparède, Montessori, Decroly, entre otros, insistieron en la necesidad de recuperar al alumno como protagonista de su propio aprendizaje. Para aprender hay que "hacer", ensayar, probar sin miedo a equivocarse. El arte, la pintura, la música o la danza formaban parte de esta expresión espontanea de los niños, base de su aprendizaje en la llamada "escuela activa". La enseñanza tradicional reduce al aprendiz a un sujeto pasivo que se limita a repetir lo ya sabido por el profesor. una común limitación; están sujetas a las lindes trazadas por nuestras

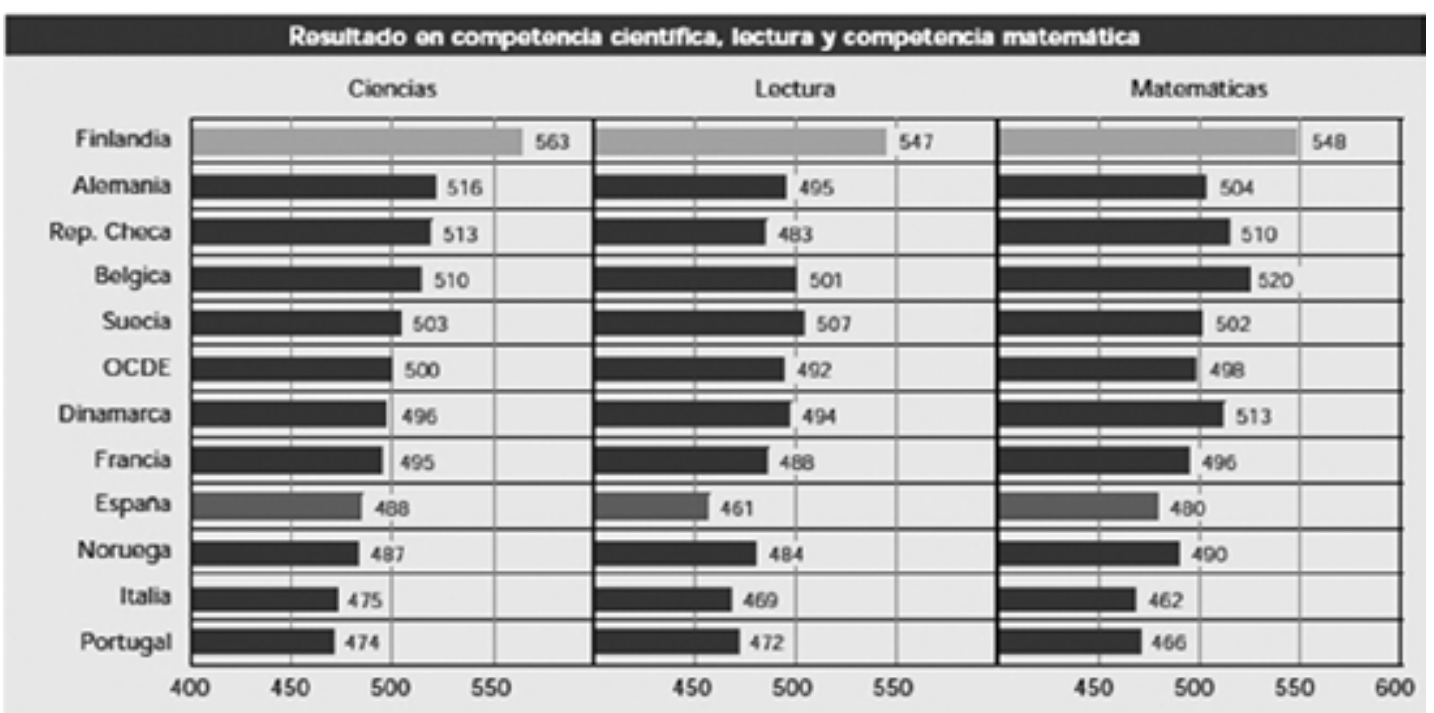

Fig. 1. Los países están ordenados por la puntuación en Ciencias. OCDE: PISA. 2006 También influye el tiempo y el espacio ya que "todas las artes tienen

sori Method New York. Fiederic A. en la educación, España, Universa. Fuente:http://www.eluniversal. com.co/suplementos/ la-importancia-del-arte-en-la-educacion-87023. frame=true\&widStokes Company, 1912, pp. 29 . 4 Cat.exp: La importancia del arte the $=9 \% 25$ height $=90 \% 25[\mathrm{Con}-1$ comunes experiencias sensoriales humanas y terrenas del tiempo y el espacio" 5 . Los niños conocen del mundo: objeto y circunstancia, ya que están compartiendo el mismo espacio y tiempo.

Desgraciadamente, durante la etapa de la crisis, la polémica sobre los recortes en el presupuesto educación han salido a la palestra. Por un lado el gobierno y los gobiernos regionales claman que tienen que recortar en algo, aunque la ciudadanía considera que es fundamental una buena educación y solicita, por este motivo, que se recorte en otras partes teniendo como ejemplos cargos de confianza y sueldos de políticos. ¿Se podrán cambiar algunas leyes educativas en España para mejorar el resultado?

En cambio en Finlandia poseen un sistema educativo totalmente diferente al nuestro, ellos integran a la vez en sus clases actividades artísticas, para potenciar el aprendizaje. Junto con el juego, durante esos descansos repartidos durante el día. Podemos verlo en este vídeo sobre la educación en Finlandia, grabada del programa "59 segundos" de RTVE. En este país reconocen que el mayor recurso son las personas, de ahí que invierten más del $6 \%$ del PIB en su formación durante toda su vida. Una educación para ser mujeres y hombres honestos y competentes, para dominar varios idiomas, para abrirse al mundo, para emplear sus medios de forma sostenible, y para compartir y colaborar. Según comentarios en el vídeo, esta educación finlandesa valora más las formas y la humanidad del docente que los contenidos a impartir. A final, los resultados son excelentes, como demuestra el informe PISA (es un estudio internacional sobre el estado de la educación en distintos países) situándola en primeros puestos en cualquier medida internacional, mientras que España está por debajo. (Fig. 1)

Puesto que la educación en Finlandia es objetivamente la mejor en 5 GRAVES, ROBERTS., \&WILSON, Norte y sur, 1966, pp. 131 
mejor educación de Europa?, tras hacernos esta pregunta, me propuse indagamos algo más sobre el sistema escolar de Finlandia:

1. No existen exámenes de alto nivel, solamente una selectividad. $Y$ hasta $5^{\circ}$ no hay calificaciones numéricas. Así no se busca fomentar la competitividad entre alumnos ni las comparaciones. Aunque Ken Robinson comenta: "No estoy en contra de los exámenes, pero sí de convertirlos en el centro del sistema educativo y a las notas en su única finalidad. (...) Si no estás preparado para equivocarte, nunca acertarás, sólo copiarás. No serás original"6

1. En las etapas de los primeros seis años de primaria los infantes tienen en todas o en la mayor parte de las asignaturas el mismo docente, que vela por la causa de que ningún alumno quede fuera.

2. Finlandia está volcada con los colegios públicos, la educación gratuita desde preescolar hasta la universidad incluye las clases, el comedor y hasta material escolar. Asigna del 11 al $12 \%$ de los presupuestos del estado y los ayuntamientos a subvencionar este tipo de educación. Por ese motivo existen pocos colegios privados. "Para un país con pocos recursos naturales más allá de la madera, han convertido a sus habitantes en sus recurso natural y debe ser igual para todos"7.

3. La jornada escolar suele empezar sobre las 8:00 de la mañana hasta las 3:00 de la tarde, con paréntesis para almuerzo a las 12:00 hasta media hora. Tienen 45 minutos de clase y luego 15 minutos de descanso en el patio. Y así los niños están relajados y atentos. Porque tiene que estar 45 minutos concentrados y 15 minutos de libertad. En total, imparten 608 horas lectivas en primaria, frente a las 875 horas de España. 4. Los profesores más preparados están en la etapa primaria. Para enseñar ellos requieren más de un 9 sobre 10 en sus promedios de bachillerato e incluso una gran dosis de sensibilidad social. Los postulantes a profesores tienen que pasar por una entrevista que valora su capacidad de comunicación, empatía, lectura; además, una demostración de aptitudes artísticas, matemáticas y aptitudes tecnológicas. Es una de las pruebas más duras de todo el país.

5. Al iniciar el curso los niños se someten a pruebas periódicas desde preescolar. Los alumnos que presenten algunos problemas pasan a clases especializadas con 5 niños por aula y profesores especializados. Es por un tiempo determinado, porque en el momento en el que mejora, se aprende igual que se aprende a leer," Espana, La vanguardia. Fuen17 de marzo de 2015]. 7 HERNÁNDEZ, SANTIAGO: Educaracterísticas del sistema, Españ Big in Finland, Fuente:http://www. biginfinland.com/educacion-en-finbre de 2013
6 AMIGUET, LLUIS: "La creatividad e:http://www.lavanguardia.com/ lacontra/20101103/54063818455/ a-creatividad-se-aprende-gual-quecación en Finlandia: Historia y andia/ [Consulta el 22 de Septiem pasan a la clase habitual, integrada por 20 alumnos. Esto también pasa en los países nórdicos.

Es un país en el que los colegios establecen presupuestos modestos, desarrollan su propio currículum, investigan y establecen nuevas tecnologías, no poseen una brecha en cuanto a logros y en el que no se deja ningún alumno excluidos o atrás.

Como puede verse la dirección es totalmente opuesta al sistema escolar español. Como consecuencia, el resultado final es impactante, en el que España tiene un 30\% de abandono escolar y cada año más, en cambio en Finlandia tienen $0,2 \%$. A lo mejor algunas personas después de leer sobre el sistema de Finlandia no estarán de acuerdo con todo. Si yo cuento mi experiencia sobre del de Corea, seguramente estarán de acuerdo con el sistema escolar de Finlandia. Corea del Sur ha conseguido un gran desarrollo económico y tecnológico en las últimas décadas. Es una sociedad cada vez más competitiva y eso se refleja, entre otros aspectos, en un sistema que prioriza la disciplina y un esfuerzo largo y prolongado ante todo. Para saber más, podemos ver el documental Corea del Sur: prohibido fracasar, del programa Informe Semanal de RTVE', que cuenta, cómo nueve de cada diez estudiantes del Corea del Sur y por la tarde acuden a las academias privadas, después de hacer los deberes. "Apenas tienen cuatro o cinco hora para dormir. Los informes señalan que son los estudiantes mejor preparados del mundo" ${ }^{9}$. Pero desgraciadamente, en la época de exámenes aumenta el número de suicidios por la presión por obtener las mejores notas. Tras las consecuencias a partir del 2012 el gobierno de Corea del Sur ha decidido cambiar el sistema escolar. Tras esta comparación, no decimos que no haya que como ocurre en el sistema educativo finlandés, no hay que esforzarse para trabajar, sino que hay otros métodos mejores. Al comparar el sistema educativo finlandés, el objetivo del nivel preescolar es fortalecer las aptitudes de aprendizaje de los niños. En la práctica se les enseñan nuevos conocimientos y capacidades a través del juego, estimulando sus capacidades y adaptándose a los problemas en el aprendizaje.

Como objeto de estudio el aprendizaje de juegos y bases teóricas en las que apoya nuestro análisis, se puede observar con claridad la educación infantil se podría mejorar bastante en nuestro país.

El arte, en todas sus expresiones, es fundamental en el desarrollo infantil. El niño dinámico, en proceso de desarrollo y de transformación toma cada vez una posición más activa en la enseñanza. La educación artística fomenta el incremento de la capacidad de acción, la experiencia, la redefinición y la estabilidad que son imprescindibles en una sociedad llena de cambios, y que además enseña a los niños a ser más abiertos y tolerantes, al permitir que éstos se expresen de forma libre y creativa. Promover el trabajo individual y colectivo incrementa la seguridad en sí mismo y aumenta el rendimiento académico en general.

En la educación artística participa el trinomio: jugar + crear + compartir, como en Finlandia, lo que pone de manifiesto que la riqueza de habilidades que posibilita el juego lo convierte en un extraordinario elemento para el aprendizaje y la comunicación. Según lo expuesto ¿no parece lógico que en la etapa escolar el tándem educación/arte conforme una herramienta idónea para motivar a los infantes y fomentar el aprendizaje activo dentro y fuera del aula? La respuesta parece evidente pero ¿Habrá un método de educación artística que pueda mejorar nuestro sistema escolar?

A partir de una comparativa con otros sistemas escolares con el de FinEspaña, Informe semanal, RT te: http://www.rtve.es/alacarta/ manal-corea-del-sur-prohibido-fracasar/1487175/ lentro del aul ) observamos que podemos mejorar tiempo, jerarquías dentro del aula... ciertos aspectos. En este artículo, planteamos que a través de la educación terminan sus clases entorno a las diez de la noche, de día van al colegio videos/informe-semanal/informe-se- 
Fig. 2. Rodaje de la película "La importancia de llamarse Applewhite" César Bona. 2010

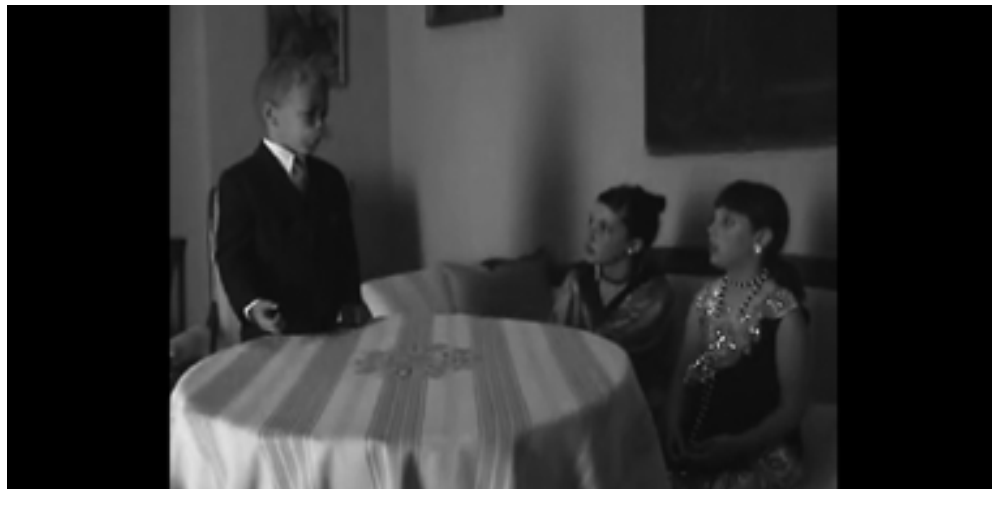

artística podemos introducir algunos de estos cambios, como recurso capaz de modificar la actividad y capacidad de aprendizaje en la educación escolar, lo que lo convierte en una herramienta clave para el aprendizaje bajo una apariencia de juego o experiencia colectiva. Autores como Ken Robinson, a nivel internacional, o María Acaso en España, apuestan con fuerza por estos nuevos modelos educativos en los que se trata de "recuperar el placer como el eje de la educación" ${ }^{10}$ y donde el arte, la ilustración, la animación, el diseño y la creatividad tienen mucho que decir.

Para ilustrar el potencial de la educación artística en las aulas con algunos ejemplos, presentaremos tres iniciativas que han llevado a cabo proyectos de éxito, y que se enmarcan en estos nuevos modelos educativos:

\section{Tocar el cajón o La importancia de llamarse Applewhite: Cesar Bona} (Nominado al Global Teacher Prize)

César Bona es un maestro al estilo de Robin Williams en la película El club de los poetas muertos, un profesor cuyo objetivo era preparar para la vida a un conjunto de perdidos universitarios. Ha sido nominado al Global Teacher Prize, un premio que reconoce la labor de un maestro extraordinario, innovador y comprometido, que ha tenido un impacto inspirador en sus alumnos y en su comunidad. Su primer trabajo público sexy: Recuperemos el placer como Fuente:http://www.mariaacaso. es/pedagogia-sexy-recuperemos-el-placer-como-el-eje-de-la-educacion/ /Consulta el 05 de Mayo de 2015].

11 RODRÍGUEZ, ANA: César Bona un español que aspira a convertirs en el mejor maestro del mundo en valores, España, Buenas noticias. Fuente:http///ebuenasnoticias. com/2015/01/02/cesar-bona-un-zaragozano-que-aspira-a-convertirse-en-el-mejor-maestro-del-mundo-gracias-a-su-compromiso-de-educar-en-valores/ [Consulta el 15 de Enero de 2015]. fue en el Colegio Fernando el Católico, en Zaragoza. Dicho centro se ubica en un lugar conflictivo, con alumnos de diversas nacionalidades, e incluso niños de diez años que no sabían leer. Ante esto Bona pensó que un buen modo de aprendizaje para los pequeños era escribir una obra de teatro que ellos luego representaran. Y el resultado fue positivo, además lo más importante es que aprendieron sin esfuerzo, pasándolo bien. En un aula había un chico, que tocaba muy bien el cajón, y Bona le pidió que le enseñara a tocar, y así fue:

Para él, soy maestro, pero no lo sé todo, ellos también nos pueden enseñar a nosotros y al dar ese paso es muy interesante porque te permite conocer lo que les gusta. Cada niño es un universo, con sus inquietudes y el lugar donde se encuentra también marca. Todos tienen sus motivaciones, por eso primero hay que conocer a los pequeños, pues la misión del maestro es mucho más que meter datos en cabeza, es ver qué se le puede ofrecer a esos niños. ${ }^{1}$
Fig. 3. Diferentes tipos de las palabras por medios de ilustraciones. Shaolan. 2013
12 GIL AMEIJEIRAS, M.T: Apreciación artistica y educación, España, Boletin de educación de las artes visuales, 1995, pp. 5 . 13 La importancia de llamarse Applewhite: 14 FRESNEDA, CARLOS: L inventora del "chino fácil", Esp nal El mundo, Fuente:http://www.elmundo.es/internacional/2014/04/30/ 536103fde2704ef54d8b457d. html IConsulta el 30 de abril de 2014].

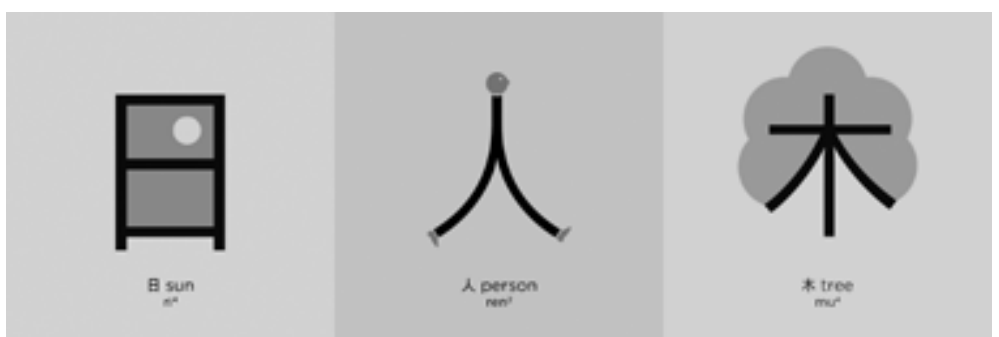

¿Qué debe ponerse al alcance de los escolares? Además, Gil Almeijeiras manifiesta la misma idea, "de llevarlo a las aulas, de ponerlo al alcance de los escolares, de darle difusión mediática y cultural para que sea descrito, analizado y estudiado, ya que forma parte, no sólo del entorno inmediato, sino de la propia vida" ${ }^{12}$. Su segundo trabajo público fue en Bureta, con 230 habitantes, donde impartió clases durante dos años. Había únicamente seis niños de edades diferentes, de entre 4 a 12. Debido a la gran diferencia de edades, César Buona decidió hacer una película de cine mudo, que fue todo un éxito, titulada La importancia de llamarse Applewhite ${ }^{13}$ (Fig. 2). Bona determinó que los protagonistas fueran dos de sus seis alumnos, dos pequeños que no se hablaban porque sus familias estaban enfrentadas. De esta manera consiguió que hablaran entre ellos y que acabaran llevándose bien.

\section{SahoLan Husueh (Diseñadora y autora de Chineasy)}

ShaoLan, nacida en Taiwan y que ahora vive en Londres, es una empresaria y escritora. "Empezó a escribir y memorizar los caracteres chinos a los cincos años. Gracias a su padre, que trabajaba como calígrafo en Taipei, se lo tomó en principio como un divertido juego" 14.

Como todo el mundo sabe, el idioma chino ha sido considerado como el idioma principal más complicado de aprender, en gran parte debido a la mayor cantidad y complejidad de sus caracteres. En el primer momento cuando ShaoLan comenzó a enseñar a sus hijos, británicos de nacimiento, se dio cuenta de lo complicado que los caracteres chinos son de aprender para un angloparlante. Fue muy complicado enseñarles. Tras decidir coger un año sabático de ser una inversionista de capital de riesgo en Londres, creó su propio método para hacer más fácil y divertido enseñarles a leer chino, al que llamó Chineasy.

El objetivo de Chineasy es ayudar a que la gente aprenda a leer chino fácilmente a través del reconocimiento de caracteres mediante ilustraciones sencillas, realizadas por la ilustradora Noma Bar. A su vez el método Chineasy tiene un gran poder mágico, pues al aprender un pequeño conjunto de bloques de construcción, los estudiantes pueden construir, formar compuestos que pueden a su vez combinar para crear diversas palabras nuevas (Fig. 3) y frases (Fig. 4). Tras dominar unas cuantas series de bloques de construcción, su aprendizaje se incrementa a un nivel completamente nuevo. Con muy poco esfuerzo, la gente es capaz de leer diversidad de frases en chino y obtener una compren- 


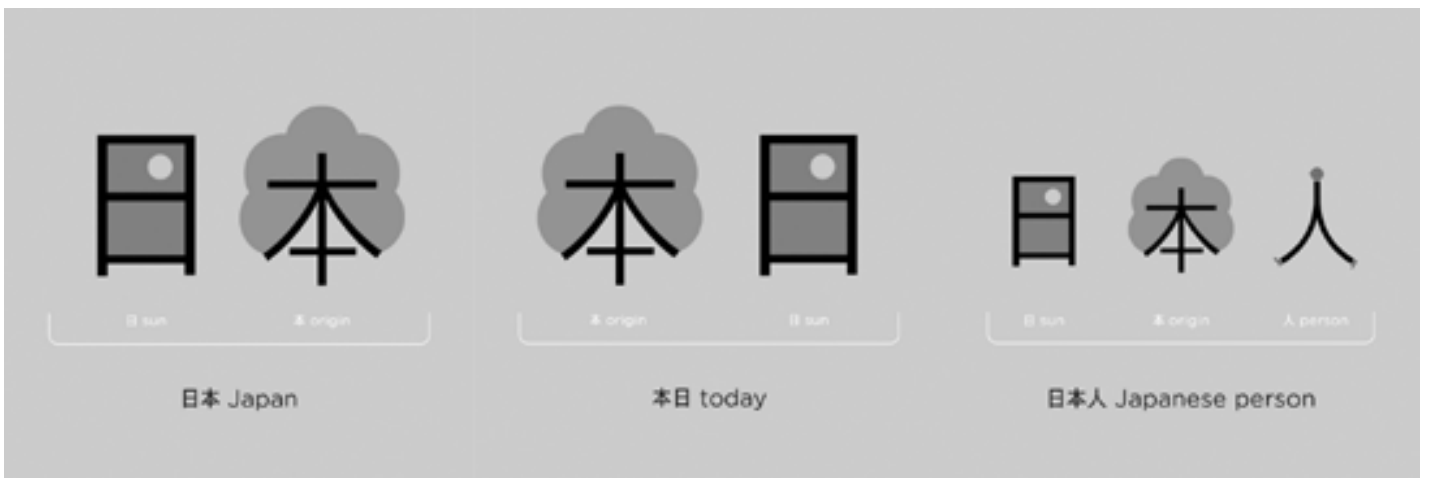

Fig. 4. Combinar para crear diversas palabras a una frase por medios
ilustraciones. Shaolan. 2013 .

15 ALYN GRIFFITHS: ALYN GRIFFITHS: Chineasy ilustrated characters designed to make learning Chinese easy, New

16 2014, pp.9.

Caravana, España, Tombs Creatius:

Companyia d'arts de carrer,

Fuente:http://www.tombscreatius,

com/puck-cinema-caravana-3/?lan-

$\mathrm{g}=$ es [Consulta el 02 de Febrero

de 2014]. sión más profunda de las influencias históricas y culturales detrás de vocabulario. "Estoy demostrando la belleza de esta profunda y antigua cultura con una interpretación moderna a través de un diseño moderno y elegante"15. Aunque existen decenas de miles de caracteres chinos, únicamente unos pocos cientos son realmente imprescindibles para entender la literatura china elemental.

Su metodología de difusión, además de a través de un libro, dispone incluso de un juego de varias tarjetas con los caracteres y con una web en la que, además de ver las ilustraciones, podemos escuchar su pronunciación. Además contamos con una serie de vídeos que facilitan el aprendizaje y un apartado donde se incluyen aspectos de la cultura china. El método también cuenta con difusión en redes sociales como Facebook, Instagram, Pinterest, Twitter, Youtube. Cuyo trabajo conduce al disfrute y fascinación, al aprendizaje a través de la experiencia.

\section{Sensacional y Puck cinema caravana: Carles Porta (co-autor)}

Carles Porta es un llustrador, diseñador gráfico, animador y artista plástico que, ha desarrollado numerosos proyectos, entre ellos Sensacional y el proyecto Puck Cinema caravana, junto a Toni Tomás (autor de Tombs Creatius)

Carles un día pensó que sería magnífico crear un espacio donde poder presentar cortometrajes de animación, a los cuales es difícil tener acceso a través de los medios tradicionales de difusión, y así nació Puck cinema caravana. Dicho espacio de proyección consiste en una caravana o roulotte (Fig. 5 y 6), decorada tanto en su interior como exterior por Porta, y con capacidad para 7 personas. Por este motivo el lema que acompaña a la caravana es: The Smallest Cinema on Earth. El objetivo de la Puck Cinema Caravana, según sus autores, es "despertar la pasión por el cine de animación. O simplemente, recuperar la experiencia del cine de una forma particular. $Y$ disfrutar un instante de una pequeña gran obra audiovisual" 16

Carles Porta ha trabajado también para espectáculos de teatro infantil como Sensacional (Fig. 7). Sensacional es un espectáculo audiovisual dedicado a infantes de 18 meses hasta 3 años, que participan activamente en la coreografia de las variadas imágenes proyectadas cenitalmente

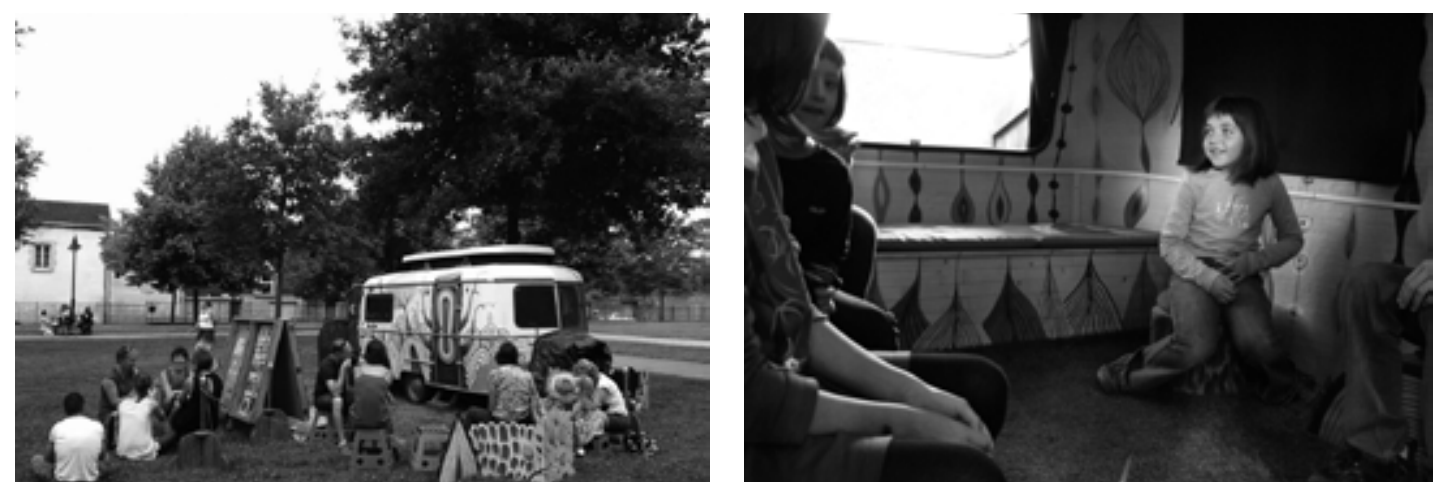

Fig. 5. Exterior de la caravana de Puck Cinema. Carles Porta. 2015.

Fig. 6. Interior de la caravana de Puck Cinema. Carles Porta. 2015 en el escenario, con una duración de 15 minutos y con la participación de un máximo de 20 infantes por sesión. Los infantes van vestidos con una camiseta blanca, como si fuera un lienzo sobre el que se proyectan formas, flores y animales. Esto les despierta mucho interés y les empuja a moverse. Los infantes y sus sombras emergen como un movimiento coreográfico que es al mismo tiempo totalmente espontáneo, un método profundo creado para producir emociones complejas. En un pequeño espacio en el que mueven las diferentes figuras, estableciendo la ilusión de que los cuerpos y las imágenes planas ocupan la misma dimensión. Los niños y niñas se guían por la fuerza de las imágenes, por el juego que éstas producen y por su sugerente banda sonora, que les lleva a experimentar, a través del juego, un mundo de variados colores, formas y sonido.

Estos tres ejemplos muestran directamente cómo beneficia la integración de las artes (cine, dibujo, música, ilustración) en el aprendizaje y en el desarrollo de habilidades imprescindibles para el mundo del trabajo y la sociedad.

\section{Conclusiones}

A modo de conclusión, podemos afirmar que las enseñanzas artísticas, vinculadas a metodologías activas en el aula, permiten que el alumno adquiera competencias específicas aplicables al resto de asignaturas y su desarrollo como persona. Competencias como: colaboración experimentación, participación activa, ilusión/placer/ juego.

Una vez llegados a este punto, deberíamos reflexionar acerca de nuestro sistema educativo, que desgraciadamente, no está exento de defectos. Se debería renovar desde el dinero destinado a la educación hasta los métodos de aprendizaje utilizados. Sencillamente no debemos olvidar que el futuro son los niños, y que recibiendo una adecuada educación moverán el universo. La educación artística puede aportar muchos beneficios elementales. El arte nos brinda un medio para conocernos, para acercarnos a nuestra propia cultura e identidad. Las actividades artísticas aumentan la percepción del entorno y, al mismo tiempo, producen en el alumno una flexibilidad de pensamiento para poder interpretar el universo que le rodea. Hay que tener en cuenta que, por medio de las diferentes modalidades artisticas, los ninos son 


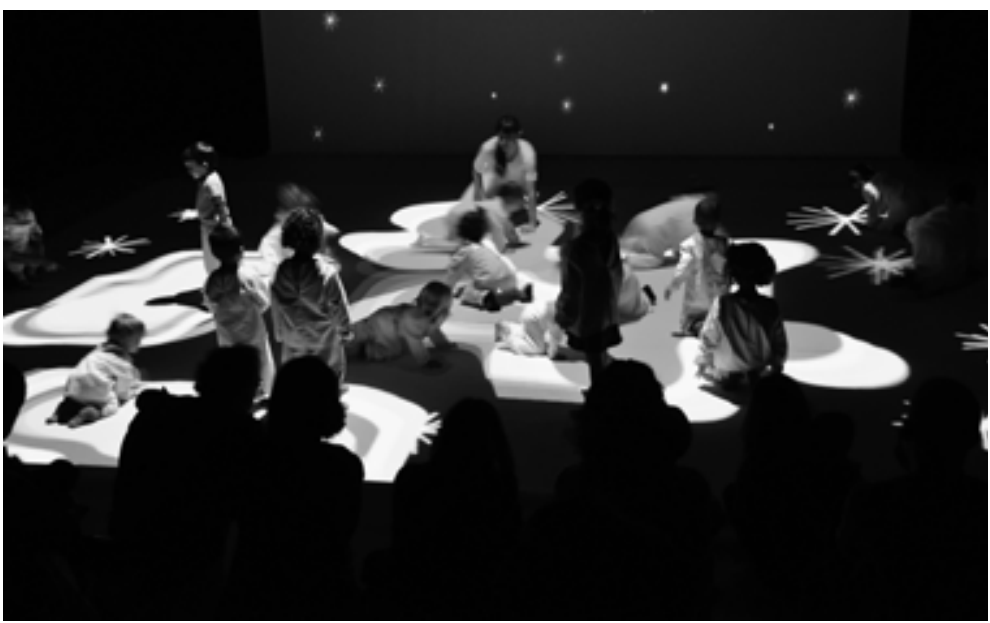

capaces de desarrollar la imaginación, la sensibilidad, la expresión, la creatividad, la percepción, el sentido del ritmo y del espacio, etc. No debemos olvidar que estos elementos tienen un peso fundamental,

ya que aportan al alumno seguridad y autonomía, aspectos esenciales para nuestra vida cotidiana. La educación artística está compuesta por saber pensar y aprender, saber comunicar, saber hacer, saber relacionar. Por otro lado, el hacer alude a la práctica, es decir, el proceso a través del cual se aprende a hacer la obra. Entretanto, el saber alude a la apreciación estética. El ser implica todas estas habilidades incluyendo la sensibilidad, el sentido crítico y la creatividad que se tienen en cuenta al crear una obra artística. Todos ellos son elementos fundamentales en el desarrollo intelectual del ser humano. La educación artística consigue impulsar las habilidades cognitivas y posibilita al individuo expresarse, comunicar a los demás a través de un lenguaje diferente y dar a conocer su obra plástica. Además el arte recurre a nuestro lado más sensible. Gracias a la educación artística, cada uno produce emociones, percibe, identifica y expresa sus planteamientos por medio de su manifestación creadora. A la vez se crea y produce, lo cual le lleva a tener una serie de emociones y de satisfacción propia al producir un nuevo fruto en forma de obra. Este modelo de educación concentra la atención y la cooperación de los niños, y supone, como en los ejemplos vistos, un punto de encuentro de niños, maestros y padres. Los propios niños se implican en lo que quieren producir y se concentran en sus metas para conseguir la obra planteada. Asimismo como se puede observar en el proyecto de César Bona, gran parte de las actividades artísticas deben de hacerse por grupos y esto significa que los infantes aprenden a trabajar en equipo con más facilidad. Ofrecen la conveniencia de explorar en nuestra imaginación y, a su vez, la capacidad de manejarse mejor en diferentes ámbitos sociales.

Además gracias a la actividad artística se desarrolla especialmente 17 KEN, ROBISON: Do Schools KII 2016.

Tengo el título de Ingeniería Técnica en Diseño Industrial y el Máster Oficial en Producción Artistica. En este articulo se recoge parte de "lando para mi tesis doctoral, bajo el lema central "aprender jugando" El objetivo principal es analizar los principales factores implícitos en la educación infantil, con la intención de proponer un modelo de participación activa a través de la educación artistica, para motiva y fomentar el aprendizaje entre los

\section{Bibliografía}

AGUILAR, M: Manual de la maestra preescolar, Barcelona, Oceano, 2007 ALYN GRIFFITHS: Alyn Griffiths. Chineasy ilustrated characters designed to make learning Chinese easy, New York evista de Dezeen, 2014

(D) sed de Cádiz 2008 AMIGUET LLUís. "L

aprende igual que se aprende a ser" España, La vanguardia.

Fente:http://www.lavanguardia.com/ lacontra/20101103/54063818455/la-creaividad-se-aprende-igual-que-se-aprendea-leer.html l Consulta el 17 de marzo do BONA CÉSAR: La importancia de llaToñ

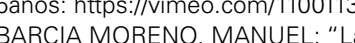
creatividad en los alumnos de educación infantil. Incidencia del contexto familiar" Revista de Creatividad y sociedad, $\mathrm{N}^{\circ} \mathrm{g}$, pp.43-52.

FRESNEDA, CARLOS: "La inventora del 'chino fácil'", España, El mundo. día, con las constantes transformaciones de realidad y contexto, pide a las personas capacidad de resolución flexible frente a distintas circunstancias, por lo que es imprescindible desarrollar capacidades de pensamiento e intervención concretos relacionadas estrechamente con la creatividad. Uno de los especialistas en creatividad, autor de "Do Schools Kill Creativity?"17. Ken Robinson, realizó una conferencia en el TED, recalcando cómo la imprevisibilidad del futuro hace difícil, por medio de la educación establecida, el formar a los niños y jóvenes para desenvolverse en un universo que no podemos siquiera vislumbrar $y_{\text {, }}$ menos aún, entender. En esta misma exposición, Robinson destaca la extraordinaria evidencia de las declaraciones de la creatividad humana en una variedad inimaginable de campos y actividades, su importancia y la capacidad de innovación que los niños tienen, siendo concretamente el desarrollo de la creatividad y de la innovación las claves para la preparación de los jóvenes de cara al futuro. nacional/2014/04/30/536103fde2704ef54d8b457d.html IConsulta el 30 de abri de 2014]

GIL AMEIJEIRAS, M.T: "Apreciación de educación de las artes visuales, 199 GRAVES, ROBERTS., \&WLSON, JOHN: El credo ar.

HERNÁNDEZ, SANTIAGO: Educación del sistema, España, Big in Finland, Fuente:http://www.biginfinland.com/ educacion-en-finlandia/ [Consulta el 22 de Septiembre de 2013].

HURLOCK, E: Desarrollo del niño, México, McGraw-Hill, 1988.

KEN, ROBISON. Do Schools Kill Creativty? Conferencia de TED, 2016.

MeNTESSORl, M. The Montessori Method, New,
Company, 1912.

PIAGET, JEAN: Play, dreams, and Imitation in childhood, New York, Norton, 1951

READ, HERBERT: Educación por el arte Buenos Aires, Paidós, 1995.

RODRIGUEZ, ANA: César Bona, un

español que aspira a convertirse en el mejor maestro del mundo gracias a artistica y educación," España, Boletín su compromiso de educar en valores. España, Buenas noticias. com/2015/00//02/cesar-bona-un-zara zano-que-aspira-a-convertirse-en-el-mejor-maestro-del-mundo-gracias-a-su-compromiso-de-educar-en-valores/ [Consul el 15 de Enero de 2015

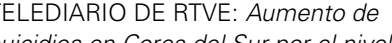
de exioncia de les esur por el nivel Fuente:http://www.rtve.es/alacartal videos/telediario/aumento-suicidios-corea-del-sur-nivel-exigencia-estudiantes/1486964/ IConsulta el 22 de Julio de 2012].

TOMÀS, TONI: Puck Cinema Caravana, España, Tombs Creatius: Companyia d'arts de carrer. Fuente:http://www. tombscreatius.com/puck-cinema-caFabrero: de 2014] [Consulta el 02

Geducación. España Universe en Fuente:http://www.eluniversal.com co/suplementos/viernes/la-importanframe=true\& width $=90 \% 25$ \&height $=90 \% 25$ [Consulta el 10 de agosto de 2012]. cia-del-arte-en-la-educacion-87023? 